\section{Survival of Apple Rootstocks to Natural Infections of Fire Blight}

\author{
D.C. Ferree, ${ }^{1}$ J.C. Schmid, ${ }^{1}$ \\ and B.L. Bishop ${ }^{2}$
}

Additional IndeX words. Erwinia amylovora, dwarfing, Malus $\times$ domestica

Summary. Survival of replicated rootstock plantings of apple trees (Malus $\times$ domestica) to fire blight (Erwinia amylovora) infection shows that a wide range of rootstock susceptibility exists. Trees on 'Malling 26' (M.26), 'Malling 9' (M.9), and 'Mark' consistently had significant losses. Of the dwarfing rootstocks widely available commercially, 'Budagovsky 9' (B.9) survived well with productive trees, but was not resistant to fire blight infection. The following experimental rootstocks had good survivability with many live productive trees in one or more trials: 'Poland 2' (P.2), 'Vineland 1' (V.1), 'Malling 27 EMLA' (M.27 EMLA), 'Budagovsky 491' (B.491), 'Budagovsky 409' (B.409), 'Vineland 7' (V.7), 'Vineland 4' (V.4), and 'Oregon Rootstock 1' (OARl).

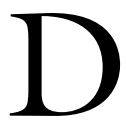
warfing rootstocks are the essential foundation of modern intensive apple orchards. Unfortunately, most of the commercially available dwarfing rootstocks are very susceptible to fire blight. Spring weather conditions in Ohio are particularly conducive to fire blight epidemics in rootstocks resulting in significant tree loss (Ferree et al., 1983). In recent years, significant tree loss has also occurred in Michigan (Perry, 1992,

Ohio State University, Ohio Agricultural Research and Development Center, Wooster, OH 44691.

Salaries and research support provided by state and federal funds appropriated to the Ohio Agricultural Research and Development Center, The Ohio State University. HCS 00-37.

${ }^{1}$ Department of Horticulture and Crop Science.

${ }^{2}$ Department of Computing and Statistical Services.
1993). Sparks (2001) indicated the fire blight epidemic in Michigan caused an \$11 million crop loss with nearly 2000 acres ( 810 ha) of apple trees lost.

Ohio's ongoing apple rootstock evaluation program has resulted in exposure of replicated plantings to fire blight epidemics. Due to the recent heavy losses, it is worthwhile to bring together tree survival results of Ohio rootstock trials.

\section{Materials and methods}

1985 Trial. In May 1985, at The Ohio State University Southern Branch near Ripley, Ohio, trees of 'MacSpur McIntosh', 'Lawspur Rome Beauty', and 'Red Chief Delicious' were planted on 22 dwarfing rootstocks (see Table 1). The trees were spaced $6 \times 16 \mathrm{ft}(1.8$ $\times 4.9 \mathrm{~m}$ ) and trained to a central leader with minimal pruning and supported by a three-wire trellis. Treatments were arranged in a randomized block design with rows maintained as single cultivars with 10 single tree replicates of 'McIntosh' and 'Rome Beauty' and five trees of 'Delicious'. Some combinations had extra trees planted and these were used in survival calculations. Yield and tree size data were previously reported (Ferree et al., 1995). Our experience in Ohio indicates that when fire blight infects the apple rootstock the tree dies and the data reported as survival from this and subsequent studies in this report are living productive trees that are functioning normally.

1990 NC-140 CULTIVAR ROOTSTOck TRIAL. NC-140 is a national committee of fruit researchers who organize uniform rootstock trials. In 1990 trials were established at 13 sites in the United States including four apple cultivars (Smoothee Golden Delicious, Nicobel Jonagold, Empire, and Law Rome) in all combinations on five rootstocks (M.9 EMLA, B.9, 'Mark,' O.3, and M.26 EMLA). Trees were spaced $8.1 \times 16 \mathrm{ft}(2.5 \times 5 \mathrm{~m})$, trained as slender spindles supported by individual stakes, and pruned minimally. Treatments were arranged as a split plot with cultivar as the whole plot and rootstock as the split plot with six individual tree replications. A summary of the growth and yield of the overall trial was presented by Autio et al. (2001).

1994 NC-140 'GALA' DWARFing ROOTSTOCK TRIAL. In 1994, 'Gala' on 18 dwarfing rootstocks (Fig. 2) was planted at 26 sites in North America. Trees were spaced $8.1 \times 14.6 \mathrm{ft}(2.5 \times$ $4.5 \mathrm{~m}$ ), trained as a vertical axe, supported by individual stakes and minimally pruned. Treatments were arranged in a randomized complete block design with 10 individual tree replications. Results of growth and fruiting for the first 5 years were presented by Marini et al. (2000). The fire blight data for these last two trials reported here are the Ohio site only.

\section{Results and discussion}

1985 Trial. The severe infections of fire blight occurred in 1989 and 1990 when these trees were 3 and 4 years old. 'MacSpur' trees had 22\% tree death, while 'Lawspur' had 24\% death with only a $12 \%$ death with 'Redchief Delicious' (Table 1). The smaller loss with 'Delicious' as the scion confirms results of a survey among commercial Ohio growers to an earlier epidemic (Ferree et al., 1983). Trees on the following rootstocks had many living functioning trees on all scion/ rootstock combinations where they were tested: B.9, V.7, V.4, OAR 1, M.7 EMLA, P.1, V.1, CG.10. Trees on M.27 EMLA, P.2, V.2, V.3, and B.146 had good survival with 'MacSpur' as the scion, but experienced more loss when 'Lawspur' was the scion. Trees on M.26 EMLA, P.22, and MAC.9 had many dead trees with both 'MacSpur' and 'Lawspur' as the scion. The resistance of some of the Vineland series of rootstocks to fire blight has been confirmed in recent inoculation trials (Cline et al., 2001). However, these are not in commercial production at the present time.

1990 NC-140 CULTIVAR ROOTSTOcK TRIAL. In 1993, fire blight infection occurred primarily in 'Law Rome Beauty' with only a few strikes occurring in the other cultivars. More than double the number of trees survived on B.9 compared to 'Law Rome Beauty' on the other four rootstocks $(P=0.099)$ (Fig. 1).

1994 NC-140 'GALA' DWARFing ROOTSTOCK TRIAL. 'Gala' has proven extremely susceptible to fire blight in Ohio and in other states that have experienced epidemic infections. 'Gala' on the following rootstocks had many living productive trees following a fire blight infection in 1996: P.2, V.1, M.27 EMLA, B.491, B.409, and B.9 (Fig. 2). Most of the clones of M.9 had severe tree losses. Two commercial 
Table 1. Survival (\%) of young apple trees planted in 1985 of three cultivars on 22 rootstocks to natural fire blight epidemics in 1989 and 1990.

\begin{tabular}{|c|c|c|c|c|}
\hline \multirow[b]{2}{*}{ Rootstock } & \multirow[b]{2}{*}{ Abbreviation } & \multicolumn{3}{|c|}{ Scion } \\
\hline & & MacSpur McIntosh & Lawspur Rome Beauty & Red Chief Delicious \\
\hline Malling 27 EMLA & M.27 EMLA & $100 a^{z}$ & $33 \mathrm{~b}$ & --- \\
\hline Poland 2 & P.2 & $100 \mathrm{a}$ & $40 \mathrm{~b}$ & 100 \\
\hline Vineland 2 & V.2 & $100 \mathrm{a}$ & $66 \mathrm{ab}$ & 85 \\
\hline Vineland 7 & V.7 & $100 \mathrm{a}$ & $100 \mathrm{a}$ & 80 \\
\hline Malling 7 EMLA & M.7 EMLA & $90 \mathrm{a}$ & $90 \mathrm{a}$ & 100 \\
\hline Poland 1 & P.1 & $90 \mathrm{a}$ & $100 \mathrm{a}$ & 100 \\
\hline Vineland 3 & V.3 & $88 \mathrm{a}$ & $50 \mathrm{~b}$ & --- \\
\hline Vineland 1 & V.1 & $88 \mathrm{a}$ & $80 \mathrm{ab}$ & 100 \\
\hline Budagovsky 146 & B. 146 & $85 \mathrm{ab}$ & $50 \mathrm{~b}$ & --- \\
\hline Poland 16 & P.16 & $64 \mathrm{ab}$ & --- & --- \\
\hline Mark & Mark & $60 \mathrm{ab}$ & $100 \mathrm{a}$ & 80 \\
\hline C.6 & C.6 & $60 \mathrm{ab}$ & $70 \mathrm{ab}$ & 100 \\
\hline Malling 26 EMLA & M.26 EMLA & $33 \mathrm{ab}$ & $40 \mathrm{~b}$ & 80 \\
\hline Poland 22 & P.22 & $10 \mathrm{c}$ & $54 \mathrm{~b}$ & 83 \\
\hline Michigan Apple Clone 9 & MAC.9 & $10 \mathrm{c}$ & $54 \mathrm{~b}$ & 85 \\
\hline
\end{tabular}

${ }^{\mathrm{z}}$ Mean separation using logistic regression $(P=0.05)$.

growers in Ohio who had large plantings of 'Gala' on M.9 and B.9 had similar results with much greater loss on M.9 than on B.9.

In 2000 , another very serious fire blight infection occurred in northern Ohio. In solid plantings on B.9, minimal tree loss occurred with very severe infection in susceptible scions such as 'Gala'. In plantings of 104 2-year-old trees of 'Scarlet O'Hara' and 'Suncrisp' on B.9, the infection was so severe in the scion that the trees were removed in the spring of 2001. Upon removal, $86 \%$ and $94 \%$ of the B.9 rootstocks were alive under these cultivars. Although not an absolute, severe losses in the field have generally occurred on trees less than 5 years old when they were carrying their first or second crop. A 25-year experimental planting of 'Jonathan' on M.9 had severe fire blight in the scion when it was 21 and again at 25 and no trees died.

Of the widely available dwarfing apple rootstocks, B.9 has consistently had a high survival rate. Although it is

Fig. 1. Survival of trees of 'Lawspur Rome Beauty' on five rootstocks to a fire blight infection in their fourth leaf. Based logistic regression $(P=$ $0.05)$ there was no stastiscal difference among rootstocks. not resistant to fire blight, tree loss of B.9 has been consistently less than on M.9 and M.26. B.9 in Ohio has been equal to M.9 in tree size, precocity, yield, yield efficiency, and fruit size. In a Michigan study where 4-year-old trees were inoculated with fire blight in the field, trees on B.9 had no rootstock infection, while loss occurred on M.9 and M.26 (Jones, 2001). It has also proven to be very yield efficient and productive in national $\mathrm{NC}-140$ trials (Autio et al., 2001; NC-140, 1996). Some nurseries have had problems with knot type growths on the roots of B.9, but to date this has not been identified as an adverse problem in the field. We have been suggesting the use of B.9 when fire-blight-susceptible cultivars are to be grown in orchard systems requiring a dwarfing rootstock.

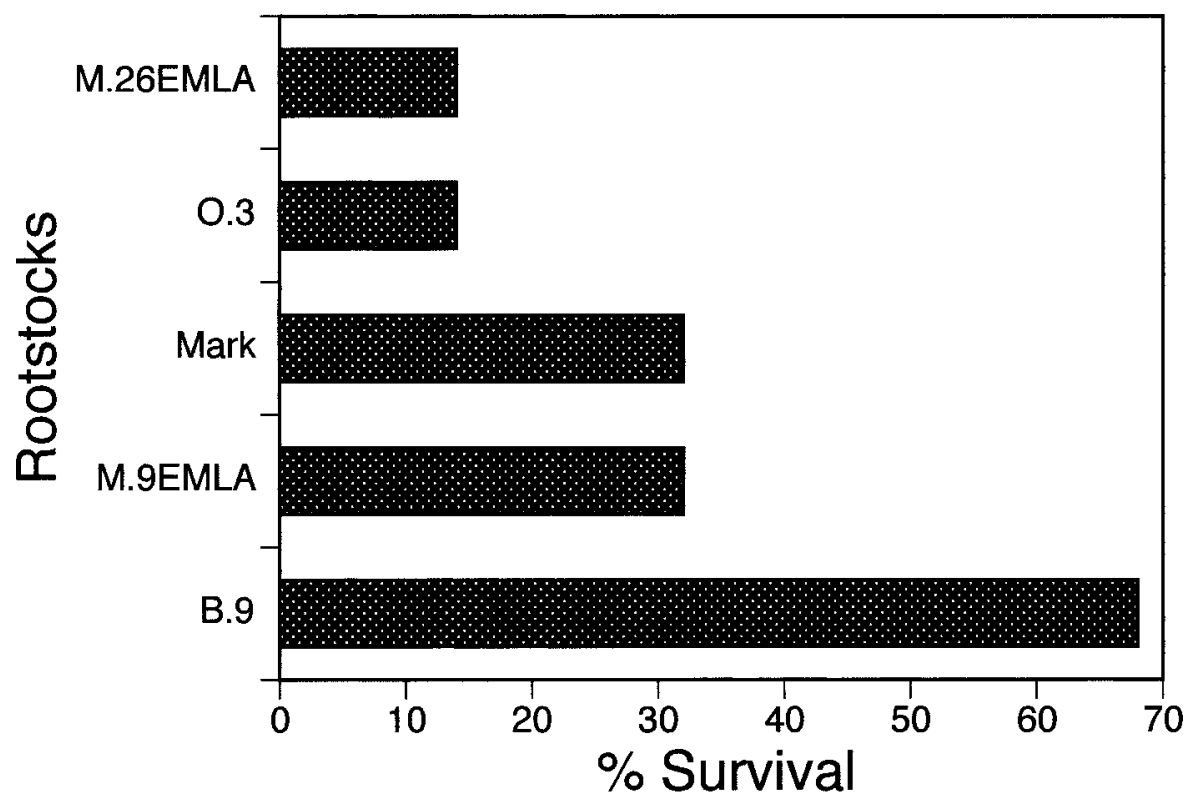




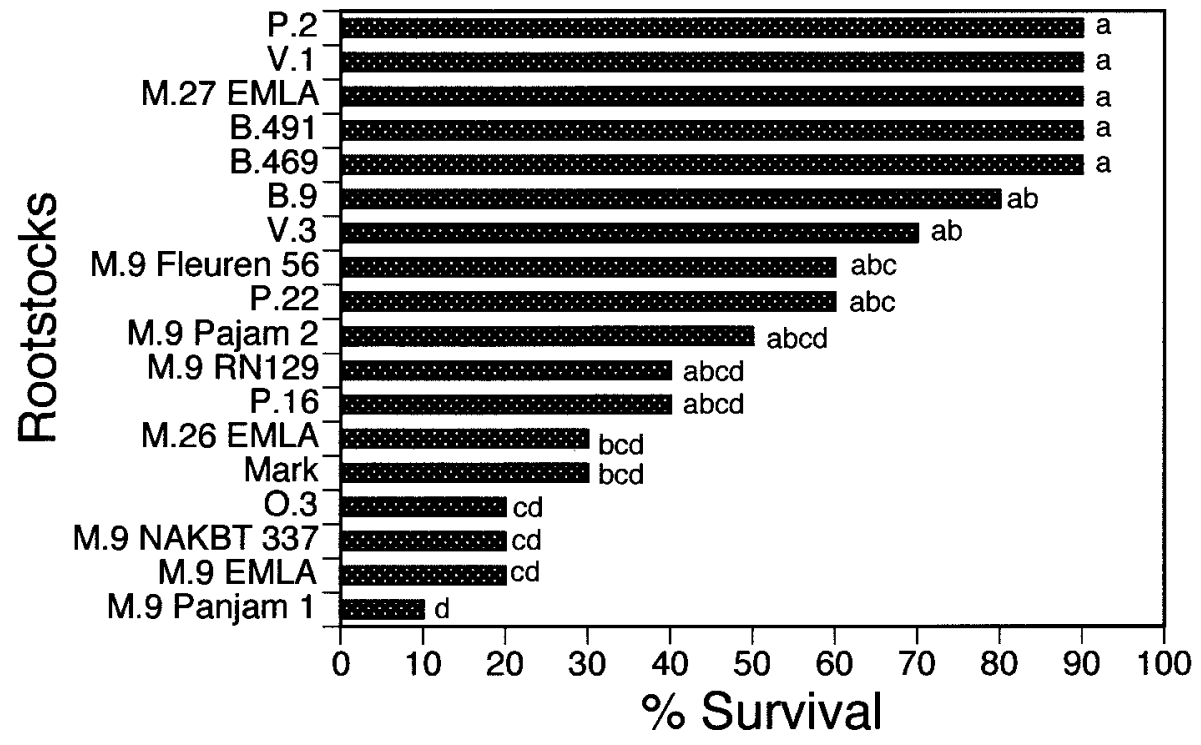

Fig. 2. Survival of 'Gala' on 18 dwarfing rootstocks to a severe fire blight infection in their third leaf. Mean separation using logistic regression $(P=0.05)$.

The ultimate solution to the loss of trees due to fire blight infection in the rootstock is to use resistant rootstocks coupled with resistant scion cultivars. It is hoped that some of the Vineland, Geneva, or other rootstock series will prove to have the necessary desirable horticultural characteristics, as well as resistance so that this problem can be avoided in the future.

\section{Literature cited}

Autio, W.R., J.L. Anderson, J.A. Barden, G.R. Brown, R.M. Crassweller, P.A. Domoto, A. Erb, D.C. Ferree, A. Gaus, R.A. Hayden, P. Hirst, F. Morrison, C.A. Mullins, J.R. Schupp, and L.D. Tukey. 2001. Performance of 'Golden Delicious', 'Jonagold', 'Empire', and 'Rome Beauty' apple trees on five rootstocks over ten years in the $1990 \mathrm{NC}-140$ cultivar/rootstock trial. J. Amer. Pomol. Soc. 55:131-137.

Cline, J.A., D.M. Hunter, W.G. Bonn, and M. Bijl. 2001. Resistance of the Vineland series of apple rootstocks to fire blight cause by Erwinia amylovora. J. Amer. Pomol. Soc. 55:218-221.

Ferree, D.C., M.A. Ellis, and F.R. Hall. 1983. Tree loss due to fire blight infection of rootstocks and interstems in Ohio apple orchards. Compact Fruit Tree 16:116120.
Ferree, D.C., P.M. Hirst, J.C. Schmid, and P.E. Dotson. 1995. Performance of three apple cultivars with 22 dwarfing rootstocks during 8 seasons in Ohio. Fruit Var. J. 49(3):171-178.

Jones, A. 2001. Michigan growers face challenge to control fire blight. Fruit Growers News (May) V40:46-49.

Marini, R.A., J.L. Anderson, W.R. Autio, B.H. Barritt, J.A. Cline, W. P. Cowgill, Jr., R.M. Crassweller, P.A. Domoto, D.C. Ferree, J. Garner, A. Gaus, G.M. Greene, C. Hampson, P. Hirst, M.M. Kushad, E. Mielke, C.A. Mullins, M. Parker, R.L. Perry, J.P. Prive, G.L. Reighard, T. Robinson, C.R. Rom, T.R. Roper, J.R. Schupp, E. Stover, and R. Unrath. 2000. Performance of 'Gala' apple on 18 dwarf rootstocks: Five-year summary of the 1994 NC-140 dwarf rootstock trial. J. Amer. Pomol. Soc. 54:92-107.

NC-140. 1996. Rootstock and scion cultivar interact to affect apple tree performance: A five-year summary of the 1990 NC- 140 cultivar/rootstock trial. Fruit Var. J. 50:175-187.

Perry, R.L. 1992. The relative susceptibility of rootstocks to fire blight. Proc. Mich. State Hort. Soc. 122:72-75.

Perry, R.L. 1993. Apple rootstock studies in Michigan. Compact Fruit Tree 26:9799.

Sparks, B. 2001. Fire blights destructive path. Amer. Fruit Grower 121(3):11-16.
Concentration by Time Product and Gas Penetration after Marine Container Fumigation of Table Grapes with Reduced Doses of Sulfur Dioxide

\author{
Carlos H. Crisosto, ${ }^{1}$ \\ Lluís Palou, ${ }^{2}$ David Garner, ${ }^{3}$ \\ and Donald A. Armson ${ }^{4}$
}

\section{Additional IndeX words. Vitis vinifera, export markets, gray mold, Botrytis cinerea, sulphur dioxide, total utilization $\mathrm{SO}_{2}$ fumigation}

Summary. Reduced doses of sulfur dioxide $\left(\mathrm{SO}_{2}\right)$ were evaluated for the fumigation of marine containers with respect to the concentration $\times$ time (CT) product and gas penetration. Two commercial export containers were loaded at $32{ }^{\circ} \mathrm{F}\left(0^{\circ} \mathrm{C}\right)$ with 20 metric pallets $[40 \times 48$ inches $(102.5$ $\times 123.1 \mathrm{~cm})]$ comprised of 72 expanded polystyrene foam boxes (12 tiers, 6 boxes/tier) of table grapes (Vitis vinifera) and fumigated with 1.0 and $0.5 \mathrm{lb}(0.454$ and $0.227 \mathrm{~kg})$ $\mathrm{SO}_{2}$, respectively. A third marine container was loaded with 20 metric pallets comprised of 84 plastic boxes of table grapes ( 14 tiers, 6 boxes/tier) and fumigated with $0.25 \mathrm{lb}(0.113$ $\mathrm{kg}) \mathrm{SO}_{2}$. The boxes contained $16 \mathrm{lb}$ $(7.3 \mathrm{~kg})$ of table grapes distributed in nine polyethylene cluster bags

Dept. of Pomology, University of California, Davis Kearney Agricultural Center, 9240 South Riverbend Ave., Parlier, CA 93648

We thank the California Table Grape Commission for financial support and Gerawan Farming (Reedley, $\mathrm{Ca}$ lif.) for providing the fruit and the export containers and allowing us to use their facilities.

${ }^{1}$ Postharvest physiologist; corresponding author, email: carlos@uckac.edu.

${ }^{2}$ Postharvest pathologist.

${ }^{3}$ Staff research associate.

${ }^{4}$ Warehouse manager, Gerawan Farming Inc., P.O Box 1249, Reedley, Calif. 